\title{
Evolutionary Medicine's Place in Nutrition and Dietetics
}

Anthony J. Basile ${ }^{1}$, David B. Schwartz ${ }^{2}$, Joseph Rigdon ${ }^{3}$, and Hamilton M. Stapell ${ }^{4}$

1. Institute of Human Nutrition, Columbia University Medical Center 2. Princeton University 3. Stanford University School of Medicine 4. State University of New York, New Paltz

\section{Introduction}

Evolutionary medicine is an emerging field that has allowed researchers to better understand health and disease. By using modern evolutionary theory, researchers can examine the diseases of today and determine their evolutionary history in hopes of developing new preventative strategies or treatments $(1,2)$. What has yet to be determined is if members of the field of nutrition and dietetics appreciate this interdisciplinary approach. Currently, the theory of evolution and evolutionary medicine education is not a requirement of accredited dietetic programs through the Accreditation Council for Education in Nutrition and Dietetics (3). Meanwhile, there has been a considerable amount of clinical research examining the effects of an evolutionary-based diet on health and disease $(4,5.6)$. Last year a systematic review and meta-analyses found that within a clinical setting an evolutionary perspective on diet was able to produce greater improvements in metabolic syndrome components compared to guideline-based control diets (7). Therefore, it appears that this interdisciplinary approach has value and can contribute the field of nutrition and dietetics.

\section{$\underline{\text { Aim and Objectives }}$}

The aim of this study it to determine the level of knowledge, acceptance and applicability of evolution and evolutionary medicine to the field of nutrition and dietetics by surveying current dietetic students and dietetic professionals. To our knowledge, a survey of this kind has yet to be performed. The objectives of the survey were 1) To determine if the theory of evolution and evolutionary medicine is covered in dietetic education programs and 2) determine if dietetic professionals and students think that an understanding of evolution can benefit the field of nutrition and dietetics.

\section{Methods}

Two separate surveys were conducted: the first surveyed dietetic students (undergraduate and graduate students as well as dietetic interns) and the second surveyed dietetic professionals (Registered Dietitians and Dietetic Technicians, Registered). Survey distribution was conducted via email and contacts for both populations were obtained from the Academy of Nutrition and Dietetics' website (eatright.org).

Education programs consisting of didactic $(n=223)$ and coordinated $(n=56)$-undergraduate and graduate programs, dietetic technician programs $(n=41)$, as well as dietetic internship programs $(n=246)$ were contacted. After removing the duplicate email addresses, the search yielded 561 unique contacts. Program directors were contacted and asked to share the survey link with their student body. The email described the survey, encouraged their participation, described the incentive for students, and for the ease of forwarding the survey, an email addressed to students was also provided.

Dietetic professionals were contacted through their state affiliates $(n=53)$, dietetic practice groups $(n=$ 36), and the "Find an Expert" page $(n=5205)$. The state affiliates and dietetic practice groups' presidents were contacted and asked to share the link-containing email request with the members of their groups. The dietetic professionals contacted through the "Find an Expert" page were sent a direct email asking for their participation. The incentive for both groups was the chance to be entered into a drawing for a \$50 Amazon gift card.

Inclusion criteria were an agreement to the consent form and self-identifying as a dietetic student or professional. The self-administered, online survey titled Outside Influence in the Field of Nutrition and Dietetics was used to collect information about evolution and evolutionary medicine's influence on the field, as well as participant's demographic data. The survey, a mix of multiple choice and write-in responses, contained a maximum of 25 questions. 
The internet-based survey website Qualtrics (qualtrics.com) was used to collect, store, and analyze the responses. The student survey was active from March $16^{\text {th }}$ to April $14^{\text {th }} 2016$ and the professional survey was active from May $24^{\text {th }}$ to July $6^{\text {th }} 2016$. Prior to the collection of data, appropriate forms were submitted to obtain permission from the State University of New York, New Paltz Human Research Ethics Board (HREB) for the use of human subjects.

\section{$\underline{\text { Participant Results }}$}

The survey was completed by 785 students and 1135 professionals. The student population came from 37 states while the professional population came from 50 states, Puerto Rico and Washington D.C. While our survey responders were a non-random sample from the target population of dietetics students and professionals, there are some signs that we can generalize these results to the field as a whole, e.g., state and age distributions of our sample were similar to those in the target population. Additionally, we took specific measures to create a generalizable sample by including every possible email contact and keeping the title neutral towards the topic of the survey.

\section{Evolution and Dietetic Education Results}

The largest group, about half of the students and professional, reported that they were somewhat familiar with evolutionary medicine, with the next largest group reporting that they were not at all familiar with the field. When asked how much information about evolution was presented throughout their education, a little less than half of participants said none, while less than one third said there was some information, and roughly a quarter said the term evolution was used but without detail. Interestingly, there appears to be an increase in the amount of coverage of evolutionary principles in dietetics education shown between the current students and past students (professionals). Furthermore, of those who reported anything other than "none" to the above questions, less than half reported that some of the evolution discussions addressed health and disease, while about a third reported that none of the discussions covered health and disease. In addition, more than half of participants either strongly agreed or agreed that they were knowledgeable of the theory of evolution, with the next largest group, roughly a quarter of the participants, responding neutrally.

\section{Evolution and the Field of Nutrition and Dietetics Results}

Collectively, the majority of students and professionals either strongly agreed or agreed that an understanding of evolution can aid the field of nutrition and dietetics. Again, the majority of participants either strongly agreed or agreed that an evolutionary perspective on health and disease would be beneficial if included in dietetics education, with a small amount responding negatively. Interestingly, the largest group, a little less than half of the participants, either disagreed or strongly disagreed when asked if they would provide an evolution explanation to a patient of client, with only about one fifth responding positively.

\section{Conclusion}

It is unlikely to see any structured education on evolution within current dietetics programs. The majority of dietetic students and professionals are in favor of the idea that an understanding of evolution would benefit the field itself and be valuable if included in dietetic education programs. Interestingly, both students and professionals report that they are knowledge about the theory of evolution; however, it was not included in their dietetic education. Furthermore, both students and professionals reported that they likely won't use evolutionary knowledge in a counseling setting. In conclusion, our survey indicates that current dietetics students and professionals are receptive to learning more about evolutionary medicine and believe that it would benefit the field of nutrition and dietetics. 


\section{References}

1. Perlman R. Evolution and Medicine. Perspect Biol Med. 2013;56:167-83.

2. Stearns SC. Evolutionary medicine: its scope, interest and potential. Proc R Soc B Biol Sci. 2012;279:430521.

3. Standards A, Education D, Leading P, Credential RD. ACEND ${ }^{\circledR}$ Accreditation Standards for Dietitian Education Programs Leading to the RD Credential. 2015;

4. Otten J, Mellberg C, Ryberg M, Sandberg S, Kullberg J, Lindahl B, Larsson C, Hauksson J, Olsson T. Strong and persistent effect on liver fat with a Paleolithic diet during a two-year intervention. Int J Obes [Internet]. Nature Publishing Group; 2016;40:1-28.

5. Whalen K a, McCullough ML, Flanders WD, Hartman TJ, Judd S, Bostick RM. Paleolithic and Mediterranean Diet Pattern Scores Are Inversely Associated with Biomarkers of Inflammation and Oxidative Balance in Adults. J Nutr. 2016;1217-26.

6. Masharani U, Sherchan P, Schloetter M, Stratford S, Xiao a, Sebastian a, Nolte Kennedy M, Frassetto L. Metabolic and physiologic effects from consuming a hunter-gatherer (Paleolithic)-type diet in type 2 diabetes. Eur J Clin Nutr. 2015;1-5.

7. Manheimer EW, van Zuuren EJ, Fedorowicz Z, Pij1 H. Paleolithic nutrition for metabolic syndrome : systematic review and. Am J Clin Nutr Nutr. 2015;102:922-32. 